\title{
Front desk talk: discourse analysis of receptionist-patient interaction
}

\author{
Heather Hewitt, Lucy McCloughan and Brian McKinstry
}

\begin{abstract}
Background

GP receptionists are the first point of contact with the NHS for most patients and have an important role in facilitating access to healthcare services. There is evidence that they are often perceived as impersonal, insensitive, or officious.
\end{abstract}

Aim

To analyse the communicative styles of GP receptionists when dealing with patients.

Design of study

Ethnographically situated discourse analysis of audio recordings.

Setting

Three NHS GP surgeries in Scotland.

Method

Fine-grained transcription and stage-by-stage analysis of digital audio recordings of 283 encounters between receptionists and patients engaged in front desk business. Participants were 16 receptionists and 283 patients.

\section{Results}

Interaction between receptionists and patients consists mainly of verbal routines that are shaped by the administrative tasks completed through them. Receptionists adhere to these established patterns of use at all times, even when dealing with non-routine situations. Within the routine framework, receptionists communicate with patients using styles that display three dominant approaches: task centred, conventionally polite, and rapport building. Receptionists who adopt a task-centred approach use forms with minimal interpersonal content, while those who use conventionally polite forms or those associated with rapport building, give attention to establishing positive relationships with patients. There is no evidence that any stylistic approach is more efficient than another. There is, however, evidence that excessive adherence to routine verbal behaviour has an adverse impact on problem solving.

\section{Conclusion}

Most receptionist discourse consists of the repetition of established verbal routines. Receptionists adopt verbal styles that are predominantly task centred, conventionally polite, or rapport building. Although all three styles enable the completion of reception work with similar levels of efficiency, task-centred styles may appear over-direct. The use of a routine approach when dealing with problematic situations can inhibit and delay their resolution.

Keywords

administrative efficiency; communication; ethnography, qualitative research.

\section{INTRODUCTION}

General practice receptionists have an important role in the delivery of primary care. For most NHS patients, they are the first point of contact with the entire service, and access is initially obtained through them. ${ }^{1,2}$ Previous studies have shown that, while receptionists assert that they wish to help patients, they are often perceived as rude, impersonal, insensitive, or officious. ${ }^{3-7}$ Although the communicative styles of receptionists are sometimes perceived as negative, this has only recently been explored through analysis of naturally occurring examples of their interaction with patients. ${ }^{8}$ In this paper, receptionists' communicative styles are analysed using audio recordings made at the front desks of GP practices. The study aim is to identify reasons for the difference between the perceptions of patients and receptionists.

\section{METHOD}

Audio recordings of interaction between receptionists and patients were made at three GP practices, in the course of 1 working day in each practice. In addition, ethnographic information was gathered through discussions with practice and reception managers, semi-structured interviews with receptionists, and observations made while receptionists went about their work. The resulting data included detailed descriptions of the working practices of receptionists as well as information about their attitudes to and experiences of front desk work. The practices were purposively sampled to

H Hewitt, PhD, research fellow; L McCloughan, PhD, programme manager, NHS Lothian; B McKinstry, MD, FRCGP, reader, Centre for Population Health Sciences: General Practice Section, University of Edinburgh.

Address for correspondence

Heather Hewitt, Centre for Population Health Sciences: General Practice Section, University of Edinburgh, 20 West Richmond Street Edinburgh EH8 9DX. E-mail: Heather.Hewitt@ed.ac.uk

Submitted: 28 August 2008; Editor's response: 23 October 2008; final acceptance: 15 January 2009.

○British Journal of General Practice

This is a full-length article of an abridged version published in print and originally published online first on 15 Jun 2009. Cite this version as: Br J Gen Pract 2009 DOI: 10.3399/bjgp09X453774 (abridged text, in print: Br J Gen Pract 2009; 59: 571-577). 
provide contrasts in size, social setting and levels of training received by receptionists (Table 1).

Following meetings to explain the study, all receptionists at each of the three practices agreed to take part in the research. A research assistant gave an information sheet and verbal explanation to all patients who were eligible to provide consent, and to parents accompanying children, as soon as they entered practices on the day of recording and, if they were willing to participate, asked them to hand in a consent form to a receptionist when they reached the front desk. Recordings were made and interaction observed.

To permit fine-grained analysis of the verbal features of the interaction, the audio recordings were transcribed in detail using a modified version of the Jefferson system in which standard orthography is supplemented by additional information about features such as pauses, hesitation, intonation, overlapping talk, and voice quality. ${ }^{9}$ Details are shown in Box 1. The names of all participants have been changed.

Conversation analysis, a methodology now increasingly adopted in primary care research, ${ }^{10}$ was then carried out to determine both how receptionist-patient talk unfolded turn by turn and sequence by sequence, and how the interactional practices used to complete different front desk activities were structured. Following this, the typical stages present in each activity were identified, ${ }^{11}$ and also the routine verbal actions through which receptionists and patients carry out their work. ${ }^{12}$ Examples of the stages and verbal actions typically present in the activity of checking in are shown in Table 2.

Following the organisation of the data into these detailed categories, a comparison was made of the different means of carrying out the same routine verbal actions. Table 3 shows a range of differing routines for making a service offer.

Finally, interpersonal styles were categorised using criteria from politeness theory. ${ }^{13}$

\section{RESULTS}

Consent was given by 16 receptionists and 283 patients. All receptionists agreed to take part. The consent rate of patients was $69.3 \%$. All 16 receptionists and 177 patients $(62.5 \%)$ were female; $92 \%$ of patients also completed questionnaires that provided information about age and sex (Table 4). This information was not available for nonconsenting patients.

Receptionists and patients were involved in 12 different types of activity. The core activities of making appointments, checking in, and ordering or collecting repeat prescriptions accounted for almost

\section{How this fits in}

General practice receptionists believe that they are doing their best for patients, sometimes in difficult circumstances, yet patients often describe them as impersonal, insensitive, or officious. The work of receptionists with patients is carried out through verbal interaction but little has hitherto been known about the structure and content of this talk. The analysis in this study of naturally occurring interaction between receptionists and patients fills this gap in knowledge of front desk work, providing evidence that, in contrast with participants in service encounters in other settings, some receptionists are extremely direct in their verbal behaviour and focus on task completion or the maintenance of bureaucratic routines to the exclusion of interpersonal concerns and attention to the voice of the patient. It is suggested that this may account for the disparity between receptionists' positive intentions and some negative perceptions of their behaviour.

Table 1. Profiles of participating practices.

\begin{tabular}{lccc} 
& Practice A & Practice B & Practice C \\
\hline Number of GPs & 4 & 7 & 7 \\
\hline Number of receptionists & 7 & 8 & 8 \\
\hline Number of patients per GPa & 1370 & 1430 & 1640 \\
\hline Social demography & $\begin{array}{c}\text { Semi-rural, } \\
\text { deprived }\end{array}$ & $\begin{array}{c}\text { Inner-city, } \\
\text { deprived }\end{array}$ & $\begin{array}{c}\text { Urban, } \\
\text { middle-class }\end{array}$ \\
\hline Receptionist training & $\begin{array}{c}\text { 3 had attended } \\
\text { specialist courses }\end{array}$ & $\begin{array}{c}\text { All had attended } \\
\text { specialist courses }\end{array}$ & $\begin{array}{c}\text { In-house } \\
\text { training only }\end{array}$ \\
\hline
\end{tabular}

${ }^{\mathrm{a}}$ Figures are rounded up or down to the nearest multiple of 10.

\section{Box 1. Transcription conventions.}

$\mathrm{R}: \quad$ receptionist

P: patient

? rising intonation

. a stop indicates the micro-interval between segments of speech

(.) a stop in round brackets indicates a pause of less than one second

(2) a number in round brackets indicates a pause timed to the nearest second

:: $\quad$ a colon indicates lengthening of a sound, with additional colons indicating further lengthening

no underlining indicates a word spoken louder than those around it

pres- a dash immediately after an item indicates that the speaker has broken off before completing the utterance

[ square brackets on successive lines indicate the beginning of simultaneous speech

$==$ equals signs indicate that there is no interval between adjacent utterances

\{mhm\} curly brackets enclose brief utterances made during another speaker's turn, which show acknowledgement of what is being said

(sighs) italicised text in round brackets indicates either contextual information or non-verbal vocalisations

hh indicates a unit of laughter 


\section{Table 2. Stages and verbal actions in a checking-in sequence.}

\begin{tabular}{llll} 
Stage & Verbal action & Speaker & Text \\
\hline Opening & Making service offer & R: & hi . could I help? \\
\cline { 2 - 4 } & $\begin{array}{l}\text { Providing reason } \\
\text { for attendance }\end{array}$ & P: & $\begin{array}{c}\text { aye . l've got an appointment } \\
\text { with Dr Moyles at ten o'clock }\end{array}$ \\
\hline Information check & \begin{tabular}{l} 
Seeking information \\
\cline { 2 - 4 }
\end{tabular} & R: & what was the name? \\
\cline { 2 - 4 } Service provision & $\begin{array}{l}\text { Informing that } \\
\text { service is available }\end{array}$ & R: & that's fine Sharon: \\
\hline
\end{tabular}

Table 3. Making a service offer.

\begin{tabular}{lll} 
Action & Approach & Examples \\
\cline { 2 - 3 } Making service offer & Greeting & Hi, Hello, Hi there, Hello there, Hiya \\
\cline { 2 - 3 } Indirect elicitation & Yes?, Who's next? \\
\cline { 2 - 3 } & Polite offer & Can I help you?, May I help you? \\
\cline { 2 - 3 } & Explicit question & Do you have an appointment? \\
\cline { 2 - 3 }
\end{tabular}

Table 4. Age and sex of participating patients who completed questionnaires.

\begin{tabular}{lccccc} 
Age, years & $15-25$ & $26-40$ & $41-60$ & $61-75$ & $>75$ \\
\hline Male & 8 & 17 & 29 & 29 & 15 \\
\hline Female & 18 & 37 & 67 & 33 & 8 \\
\hline Total & 26 & 54 & 96 & 62 & 23 \\
\hline
\end{tabular}

Table 5. Front desk activities.

\begin{tabular}{|c|c|c|c|c|}
\hline \multirow[b]{2}{*}{ Activity } & \multicolumn{4}{|c|}{$n(\%)$} \\
\hline & Practice A & Practice B & Practice C & Total \\
\hline $\begin{array}{l}\text { Checking in for } \\
\text { appointment }\end{array}$ & $31(36.5)$ & $60(48.4)$ & $58(59.8)$ & $149(48.7)$ \\
\hline Making appointment & $15(17.6)$ & $14(11.3)$ & $13(13.4)$ & $42(13.7)$ \\
\hline $\begin{array}{l}\text { Collecting repeat } \\
\text { prescription }\end{array}$ & $16(18.8)$ & $35(28.2)$ & $13(13.4)$ & 64 (20.9) \\
\hline $\begin{array}{l}\text { Ordering repeat } \\
\text { prescription }\end{array}$ & $14(16.5)$ & $4(3.2)$ & $1(1.0)$ & $19(6.2)$ \\
\hline Prescription query & $7(8.2)$ & $3(2.4)$ & $2(2.1)$ & $12(3.9)$ \\
\hline Other query & - & $4(3.2)$ & $3(3.1)$ & $7(2.3)$ \\
\hline Registration & $1(1.2)$ & $1(0.9)$ & $2(2.1)$ & $4(1.3)$ \\
\hline Letters & - & $3(2.4)$ & $1(1.0)$ & $4(1.3)$ \\
\hline Organising a reminder & $1(1.2)$ & - & - & $1(0.3)$ \\
\hline Dealing with test sample & - & - & $1(1.0)$ & $1(0.3)$ \\
\hline$\underline{\text { Deliveries }}$ & - & - & $2(2.1)$ & $2(0.7)$ \\
\hline Ordering a cab & - & - & $1(1.0)$ & $1(0.3)$ \\
\hline
\end{tabular}

$90 \%$ of all encounters, with queries covering a further $6 \%$ and registrations just over $1 \%$ (Table 5).

The three main stages through which activities were carried out were opening, information check, and service provision. Two or more verbal actions were completed during each stage. During opening, receptionists made service offers and patients gave reasons for attendance; during information check, receptionists (or patients) asked for information, which patients (or receptionists) provided; during service provision, receptionists issued information and/or instructions, which patients accepted or rejected. In the case of patient rejection there was repetition of stages; in the case of patient acceptance, encounters were then brought to a close (Table 6).

When different ways of carrying out the same action were compared, individual receptionists were found to have three dominant communicative approaches. These can be described as task centred, conventionally polite, and rapport building. The former was factual with no direct verbal expression of interpersonal awareness, the second was exemplified by the use of formally polite language, and the third was characterised by language in which attempts were made to show friendliness or to build rapport with patients.

\section{Routine language styles}

The contrasts between the three dominant approaches are shown clearly when the different ways in which receptionists carry out routine verbal actions in each stage of an encounter are compared. In task-centred encounters, receptionists offer service by elicitation, make information checks through direct questions, and issue service instructions or information through imperatives, direct statements, or brief acknowledgements (Box 2, A). In conventionally polite encounters, receptionists use indirect questions to offer service, gather information using indirect requests, and issue service instructions or information using modal verbs such as 'could' and 'would', and conditional constructions with 'if' (Box 2, B). In rapport-building encounters, receptionists offer service implicitly through greetings and personalise their routine behaviour with an overlay of less formal relational talk, for example by using first names to address patients, making brief personal comments, and sharing laughter (Box 2, C).

Individual styles are subject to constant adjustment in response to reactions from conversational partners, leading to the alternation or combination of different approaches by the same speaker. Nevertheless, although receptionists did not always adhere rigidly to one format, different approaches were dominant in the speech of different individuals and at different practices. The receptionists at Practice $B$ showed the most awareness of customer relations by making use of one of the more patient-centred styles, those at Practice $C$ paid the least attention to interpersonal 
concerns, and those at Practice A fell between the other two practices, showing wide variation in their communicative choices.

\section{Non-routine comments from patients}

Although most of the front desk talk of patients was restricted to routine matters, there were occasions when less predictable topics were introduced. These situations were the most revealing of the communicative approaches of receptionists. Receptionists who took a strongly task-centred approach ignored all patient comments, including apologies and attempts at small talk, and maintained a narrow focus on task completion. Receptionists with more patient-centred communicative styles were likely to acknowledge apologies, respond to small talk and, if patients were well known to them, engage in teasing and shared laughter. Examples of the contrasting styles are shown in Boxes 3 and 4 . In the extract in Box 3 the receptionist continues with her routine, ignoring the personal information which the patient volunteers, whereas the receptionist in the extract in Box 4 not only acknowledges and develops the personal topic that is introduced by the patient, but also shares laughter with him.

\section{Non-routine service situations}

Routine procedures at the three reception desks did not always run smoothly. For instance, there were sometimes long waits for patients or failure to meet their precise appointment needs. There were also occasional administrative errors, particularly in the issuing of prescriptions and the handling of test samples. Although receptionists successfully resolved the problems that resulted from these errors, in doing so some omitted interpersonal aspects of communication, disclaimed responsibility, and failed to apologise. Efficient communication was also sometimes hampered when receptionists adhered to routines but did not attend to the non-routine concerns of patients. This is illustrated by the extract in Box 5, in which the non-routine situation is the loss of the patient's test sample.

There are three occasions in this encounter (highlighted in bold font) when the receptionist shows that she has not grasped the details of the patient's problem. The first comes immediately after the patient's lengthy exposition (lines 1-6 and 8-9). Although the receptionist's acknowledgement tokens (lines 3 and 4) suggest that she is listening carefully, when she takes her own turn it becomes apparent that she is responding only to the patient's request to see her GP (lines 4-5). Thus, she first indicates that the doctor is not currently available (line 10) and then offers a telephone appointment (line 12), not taking into account the patient's earlier announcement that
Table 6. Verbal actions carried out at each stage.

\begin{tabular}{lll} 
Stage & Speaker & Action \\
\hline Opening & Receptionist & Make service offer \\
\cline { 2 - 3 } & Patient & Provide reason for attendance \\
\hline Information check & Receptionist/patient & Seek information \\
\cline { 2 - 3 } & Patient/receptionist & Provide/not provide information \\
\cline { 2 - 3 } & Receptionist/patient & Seek confirmation \\
\cline { 2 - 3 } & Patient/receptionist & Confirm/not confirm \\
\hline Service provision & Receptionist & Inform/instruct \\
\cline { 2 - 3 } & Patient & Accept/reject \\
\hline
\end{tabular}

\section{Box 2. Interpersonal approaches of receptionists in} checking-in routines.

A: Direct
$\mathrm{R}$ : yes
P: nine twenty . Dr Glasgow
R: yes . I've booked you in . that's alright

B: Conventionally polite
$\mathrm{R}$ : can I help you?
P: got an appointment at ten o'clock with Dr Glasgow
$\mathrm{R}$ : and your name please?
P: Carole Hillenbrand
R: aha . okay . if you'll just have a seat in the waiting room please

- C: Rapport building
R: hi there
P: hi . got an appointment for: Robin Ritchie at twenty to two
$\mathrm{R}$ : aha
P: or twenty to three sorry
$R$ : what was your name [please
P: $\quad[$ hhhh . Anne Alem
R: hh hh
P: ha ha ha ha ha ha
R: [ha ha ha ha. Right Anne
P: memory's away and a'
(...)
R: ((to patient's small children)) hello girls
$\mathrm{R}$ : have you been good girls for your mum?
(1)
$\mathrm{P}: \quad$ the three lassies? . no
(.)
$\mathrm{R}: \mathrm{no}$ ?
P: nah [they do nothing but fight
((continues)) 


\section{Box 3. Task focus.}

R: can he come at . four forty-five on the twenty-eighth?

$P$ : that's fine

(.)

P: oh . that's his birthday!

$\mathrm{R}$ : what's the first name?

P: eh . Martin (.) four forty-five

\section{Box 4. Rapport building.}

$\begin{array}{ll}1 \mathrm{R}: & \text { will I write it down for you? or } \\ 2 \mathrm{P}: & \text { please . if you don't mind } \\ 3 \mathrm{R}: & \text { yep }\end{array}$

(3)

4 P: $\quad$ got a full appointment diary you see and you've got to keep

5 it [up to date

$6 \mathrm{R}: \quad$ [hh hh aye [got a busy. busy life style

$7 \mathrm{P}: \quad$ [hh hh. what you laughing at?

8R: $\quad$ hh hh hh hh hh repeat prescription. While waiting for the prescription slip she has begun a conversation with another patient who is queuing at the desk. After a break of approximately 20 seconds the receptionist returns with the prescription slip, at the same time checking that the patient has no additional needs, and receiving a polite confirmation (lines $1-3$ ). There is then a micro-pause (line 4) during which the two patients resume their conversation. The receptionist attracts the patient's attention by calling out her first name before issuing a sharp instruction in a style reminiscent of a teacher-pupil exchange (line 5-6). The patient shows contrition (line 7), after which the receptionist persists with her instruction (line 8) before returning to routine business.

\section{DISCUSSION}

\section{Summary of main findings}

This study uncovers features of receptionists' communicative styles that may give rise to negative perceptions of their behaviour, showing that there are occasions when receptionists omit interpersonal aspects of communication or fail to attend to the patient's voice, perhaps because they are concentrating on task completion or because they are adhering to entrenched verbal routines. There is no evidence that adopting an impersonal verbal style allows receptionists to complete their work more quickly or resolve service requests more successfully. ${ }^{8}$ The discourse of receptionists consists to a large extent of repetition of the verbal routines that allow them to accomplish front desk tasks efficiently. Unconsidered application of these routines can lead either to coercive behaviour or to neglect of the patient's concerns, in the latter case resulting in misunderstanding and reduced efficiency, since the length of an encounter is extended when communication problems have to be sorted out.

\section{Strengths and limitations of the study}

For the first time, a corpus of examples of naturally occurring encounters between receptionists and patients has been created, providing an authentic record of front desk talk and an opportunity to observe how receptionists actually carry out their work. The corpus consists of a cross-section of routine front desk interactions but includes no examples of violent or abusive behaviour by patients. This was observed during data collection but did not involve consenting patients. There are also precedents which suggest that the study would have been enhanced if video rather than audio recordings had been obtained, ${ }^{14}$ but neither these nor detailed observations on the non-verbal behaviour of participants were available because of ethical constraints resulting from the presence of non- 
consenting patients at front desks at the time of recording. Analysis of the corpus has revealed the patterns of variation in receptionist communication that could give rise to both negative and positive judgements of their performance. Although the study is based on a broad sample of 16 receptionists and 283 patients, the self-selection of participants and their awareness that recordings were being made may have affected their behaviour. In future studies it may also be useful to obtain stimulated recall of the interaction from participants. ${ }^{15}$

\section{Comparison with existing literature}

Recent studies that consider the work of GP receptionists have discussed their position within the organisational framework of primary care and their role in ensuring that bureaucratic procedures are followed, ${ }^{16,17}$ clearly demonstrating their importance as the public face of a practice and the first point of contact for patients. In addition, it has been pointed out that a practice is a 'human service organisation', which ideally demands an empathic affective stance from its staff. ${ }^{18}$ Studies of receptionists in specialist clinics confirm the relationship between communicative behaviour and outcomes for patients. ${ }^{19,20}$ It is known both that the use of personalised language by service providers has a positive impact on customer relations, ${ }^{21}$ and that health treatment outcomes improve when there is a personal element in the interaction between patients and practitioners. ${ }^{22}$ There is also recognition that strict adherence to task-focused communication routines has a negative effect, particularly so when institutional procedures repeatedly take precedence over interpersonal concerns. ${ }^{23}$ This study shows how, at times, the bureaucratic responsibilities of receptionists institutionalise their communicative behaviour, narrowing the focus of their attention and leading to omission of the small signals of politeness or rapport that help to oil the wheels of communication. It may thus account, at least in part, for the negative view of receptionists expressed by some patients.

\section{Implications for future research and clinical practice}

Training in language use cannot be prescriptive, ${ }^{24}$ because the appropriateness of different styles varies with speakers and situations. There are occasions such as emergencies when directness is essential, and contexts in which conventional politeness may appear over-distant or a rapportbuilding approach over-familiar. ${ }^{13}$ There is, nevertheless, a case for making receptionists aware that effective work with patients must involve careful listening and some level of personal attention, as well

\section{Box 5. Test problem.}

(opening omitted)

1 P: I had a letter from Dr Maxwell this morning to say the bowel

2 test I had handed in (.) they hadn't received it and that's

3 nearly four weeks ago $\{\mathrm{R}: \mathrm{mhm}\}$ and I phoned and told her

4 secretary that it was returned $\{R: \mathrm{mhm}\}$ immediately . and I

$5 \quad$ just wondered if Dr Maxwell was available (.) to see what's

6 gonna happen now because l'm going on holiday next week

7 R: $\quad$ well . l'll tell you . e:m

(several lines omitted)

$10 \mathrm{R}$ : aye . they're due to start surgery

$11 \mathrm{P}$ : aye

$12 \mathrm{R}: \quad \mathrm{em}$. would you be able to phone in on Monday's speaking [time

$13 \mathrm{P:} \quad$ [no .

$14 \quad$ I'm away on holiday [as I was saying

$15 \mathrm{R}: \quad$ [oh . you're away on Monday . oh

16-23 (P again explains holiday plans and expresses fear that she will have to repeat the test)

$24 \mathrm{R}: \quad \mathrm{e}: \mathrm{h}$. well I would imagine if that was the case they

25 would get in touch with you

26-30 ( $\mathrm{P}$ again explains that the doctor has been trying to get in touch with her)

31 R: what's your name?

32 P: $\quad$ Mrs Susan Grayling

(8)

$33 \mathrm{R}$ : and what's your date of birth?

$34 \mathrm{P}$ : twenty-nine three thirty-two

(.)

$35 \mathrm{R}$ : and Dr Maxwell's been trying to contact you you say?

36-37 ( $\mathrm{P}$ confirms that the doctor has been trying to contact her)

$38 \mathrm{R}$ : right . if you want to have a wee seat l'll see if I can get

P 39 in touch with Dr Greene to . eh . with Dr Maxwell \{P: Maxwell\}

40 to let her know that you're in . and you wanted to know

$41 \quad$ a

$42 \mathrm{P}: \quad$ no

$43 \mathrm{R}:$ no?

$44 \mathrm{P}$ : no . I. sh- . they (lowers voice) you have lost my bowel test

45 that I handed in here

$46 \mathrm{R}: \quad$ oh . (lowered voice) right . right . aha

47-54 (P restates details of problem)

$55 \mathrm{R}: \quad$ no . no .right . if you just have a seat (.) I'll see what I

$56 \quad$ can do

as the successful completion of administrative routines. Training provision for reception staff currently remains patchy (personal communication 


\section{Box 6. Prescription problem.}

\author{
$1 \mathrm{R}: \quad$ is that it Carol? \\ $2 \mathrm{P}$ : that's everything thanks \\ $3 \mathrm{R}$ : right
}

$4 \quad($.

( $(\mathrm{P}$ continues conversation with another patient who is waiting at the desk))

$5 \mathrm{R}: \quad$ if you need this one ((repeat prescription)) . Carol .

6 finish with me first please would you

$7 \mathrm{P}: \quad$ sorry

8 R: okay . before you have your chats. ehm . that one

9 . if you want it after you've seen the doctor let me know

Association of Medical Secretaries, Practice Managers, Administrators and Receptionists, and local providers of training course). The authors believe that this study provides further evidence that the situation needs to change and they therefore support the view that an increase in the resources committed to receptionist training would lead to benefits for patients.

\section{Funding body}

The $\mathrm{PhD}$ on which this paper is based was partly financed by an Edinburgh University Standard Studentship

Ethical approval

Lothian research ethics committee (LREC/2002/7/27)

\section{Competing interests}

The authors have stated that there are none

\section{Acknowledgements}

We would like to thank the patients and receptionists who took part in the study and the practice managers and Lothian Primary Care Research Network members who facilitated it. We are also very grateful to Hugh TrappesLomax and Miriam Meyerhoff, who co-supervised the project, and to Ninian Hewitt and Pat Matthews for their support.

\section{Discuss this article}

Contribute and read comments about this article on the Discussion Forum: http://www.rcgp.org.uk/bjgp-discuss

\section{REFERENCES}

1. Colin-Thomé D. Foreword. A responsive and high quality local NHS: the primary care progress report 2004. http://www.dh.gov.uk/en/Publicationsandstatistics/Publications/Publi cationsPolicyAndGuidance/DH_4079396 (accessed 23 Jun 2009).

2. Gallagher M, Pearson P, Drinkwater C, Guy J. Managing patien demand: a qualitative study of appointment-making in general practice. Br J Gen Pract 2001; 51(465): 280-285.

3. Copeman J, van Zwanenberg T. Practice receptionists: poorly paid and taken for granted? J R Coll Gen Pract 1988; 38(306): 14-16.

4. Eisner $M$, Britten $N$. What do general practice receptionists think and feel about their work? B J Gen Pract 1999; 49(439): 103-106.

5. Arber S, Sawyer L. The role of receptionists in general practice. A 'dragon behind the desk'? Soc Sci Med 1985; 20(9): 911-921.

6. Scottish Consumer Council. Access to primary care services in Scotland. Glasgow: Scottish Consumer Council, 2001.

7. Stokes T, Dixon-Woods M, Williams S. Breaking the ceremonial order: patients' and doctors' accounts of removal from a general practitioner's list. Sociol Health Illn 2006; 28(5): 611-636.

8. Hewitt H. Front desk talk: a study of interaction between receptionist and patients in general practice surgeries. $\mathrm{PhD}$ thesis, University of Edinburgh, 2006. http://hdl.handle.net/1842/1482 (accessed 29 April 2009).

9. Maxwell Atkinson J, Heritage J. Jefferson's transcript notation. In Maxwell Atkinson J, Heritage J (eds). Structures of social action: studies in conversation analysis. Cambridge: Cambridge University Press, 1984: ix-xvi.

10. Maynard D, Heritage J. Conversation analysis, doctor-patient interaction and medical communication. Med Educ 2005; 39(4): $428-435$.

11. Byrne P, Long B. Doctors talking to patients: a study of the verbal behaviour of general practitioners consulting in their surgeries. London: HMSO, 1976.

12. Kuiper K, Flindall M. Social rituals, formulaic speech and small talk at the supermarket checkout. In: Coupland J (ed). Small talk. Harlow: Pearson, 2000; 183-207.

13. Watts R. Politeness. Cambridge: Cambridge University Press, 2003.

14. Pendleton D, Schofield T, Tate P, Havelock P. The consultation: an approach to learning and teaching. Oxford: Oxford University Press, 1984.

15. Lyle J. Stimulated recall: a report on its use in naturalistic research. $\mathrm{Br}$ Educ Res J 2003; 49: 861-878.

16. Greenhalgh T, Voisey C, Robb N. Interpreted consultations as 'business as usual'?: An analysis of organisational routines in general practice. Soc Health Illn 2007; 29(6): 931-954.

17. Offredy M. Access to primary care: decision making by GP receptionists. Br J Community Nurs 2002; 7(9): 480-485.

18. Huntington J. A care-led NHS? In: Meads G (ed). A primary care-led NHS: putting it into practice. Edinburgh: Churchill Livingstone, 1996; $1-10$.

19. Cicourel A. The interaction of cognitive and cultural models in health care delivery. In: Sarangi S, Roberts C (eds). Talk, work and the institutional order: discourse in medical, mediation and management settings. Berlin and New York: Mouton de Gruyter, 1999; 183-224.

20. Jean Y. Inclusive intake screening: shaping medical problems into specialist-appropriate cases. Sociol Health Illn 2004; 26(4): 385-410.

21. Goodwin C, Gremler D. Friendship over the counter: How social aspects of service encounters influence consumer service loyalty. In: Swartz T, Bower E, Bowen D, Brown S (eds). Advances in services marketing and management. London: JAI Press Inc, 1996; 247-282.

22. Walsh I. Small talk is 'Big Talk' in clinical discourse. Top Lang Disord 2007; 27: 24-36.

23. Sarangi S, Slembrouck S. Language, bureaucracy and social control. London: Longman, 1996.

24. Cameron D. Good to talk? Living and working in a communication culture. London: Sage, 2000. 